\title{
NOSOCOMIAL URINARY TRACT INFECTIONS, AND THEIR SUSCEPTIBILITY TO ANTIMICROBIAL AGENTS IN SPINAL CORD INJURY PATIENTS AT A REHABILITATION SETTING
}

\author{
Syeda Sarah Naqvi, Amir Waheed Butt*, Syed Ali Raza Ali Shah \\ Combined Military Hospital Kohat/National University of Medical Sciences (NUMS) Pakistan, *Armed Forces Institute of Rehab Medicine/National University of \\ Medical Sciences (NUMS) Rawalpindi Pakistan
}

\section{ABSTRACT}

Objective: To identify frequency of nosocomial urinary tract infections along with their antibiotic susceptibility in spinal cord injury patients.

Study Design: Cross-sectional study.

Place and Duration of Study: Acute Spinal Ward, Armed Forces Institute of Rehabilitation Medicine, Rawalpindi, Pakistan Apr to Oct 2016.

Methodology: Total 120 male and female patients of ages (18-70 years) with acute (>6 months) or chronic (>6 months) spinal cord injury admitted for rehabilitation and developing urinary tract infection 48 hours after admissionwere included. Patients whose culture results have polymicrobic bacteriuria samples, immune deficiency disorder and immunosuppressive therapy were excluded. Urine samples of all admitted patients suspected having urinary tract infections were collected and send to Armed Forces Institute of Pathology for culture sensitivity test showing isolated causative microorganisms and their antibiotics susceptibility.

Results: About $34.58 \pm 12.59$ years was mean age, 120 patients were included. In these were $97(80.80 \%)$ male and $23(19.20 \%)$ females with male to female ratio of $4.2: 1$. Frequency of nosocomial urinary tract infections was found in 83 (69.17\%) and no nosocomial urinary tract infections in 37 (30.83\%) patients. This study shows the frequency of antibiotic susceptibility in spinal cord injury patients as follows; Amikacin in 111 (92.50\%), Gentamicin in 108 (90\%), Imipenemin 113 (94.17\%), Tazocin in 115 (95.83\%), Ceftriaxone in 105 (87.50\%), Nitrofurantoin in $89(74.17 \%)$ and Ciprofloxacin in $96(80.0 \%)$ patients.

Conclusion: This study shows that frequency of nosocomial urinary tract infections in spinal cord injury patients is high and tazocin and imipenem are the most sensitive antibiotics.

Keywords: Antibiotic susceptibility, Spinal cord injury, Urinary tract infections.

\footnotetext{
This is an Open Access article distributed under the terms of the Creative Commons Attribution License (http://creativecommons.org/licenses/by/4.0), which permits unrestricted use, distribution, and reproduction in any medium, provided the original work is properly cited.
}

\section{INTRODUCTION}

Frequency of patients reporting to hospitals due to spinal cord injuries (SCI) is on the rise. It has different effects, ranging from Patients' own physical and mental wellbeing, to effects on his family and economic budget of the health care providers. These patients are at increased risk of developing Hospital Acquired Infections (HAIs) particularly urinary tract infection $(\mathrm{UTI})^{1}$. Urinary tract infections are the commonest infection in spinal cord injury occurring at a rate of 2.5 events per patient per year. Urinary stasis due to neurogenic bladder is present in most cases, and it leads to bacterial colonization. Bladder catheterization adds more microorganisms in urinary tract, and is a risk factor.

Studies have shown that around 22\% will develop UTI in first 50 days of their injury ${ }^{2}$. Prospective study having 64 catheter-free SCI patients demonstrated UTI

Correspondence: Dr Syeda Sarah Naqvi, Graded Rehab Specialist, Main OT, CMH Kohat Pakistan

Received: 28 May 2019; revised received: 20 Aug 2019; accepted: 26 Aug 2019 incidence of 1.82 episodes per person per year ${ }^{3}$. Stamm reported a higher incidence of infection with $\mathrm{ICs}^{4}$. Prospective study having 128 patients expressed the incidence of UTI as number of episodes per 100 patients daily or persons/day. They reported overall incidence of 0.68. The incidence in Patients who were managed with ICs, clean intermittent catheterization, condoms (males), suprapubic stimulation (females) and normal voiding, the rates were $2.72,0.41,0.36,0.34$ and 0.06 , respectively 5 . This not only results in longer stay in hospital, but it is also attributed to increase the mortality in patients suffering from $\mathrm{SCI}^{6}$. In a similar study conducted by Bilge and his colleagues, it was seen that the most common HAIs were UTI in spinal cord injury patients (276 [66.3\%] of the $416 \mathrm{HAI}$, incidence rate 4.8 cases per 1000 patient days). Also, it showed that type of bacteria and its response to various antibiotics can be different in different settings. Also, bacteria may acquire resistance to the antibiotics being used in a particular set up $\mathrm{p}^{7}$.

In a study conducted by Amin $\mathrm{M}$ and collegues it was seen that the most common isolates were E-coli 
and this bacterium was most sensitive to amikacin $(90.5 \%)$, ceftriaxone $(90.5 \%)$, gentamicin $(90.5 \%)$, ciprofloxacin $(85.3 \%)$ and nitrofurantoin (71.2\%). Amikacin and ciprofloxacin were effective antibiotics against Gram-positive cocci $(90.6 \% \text { \& } 85.9 \% \text { respectively })^{8}$. Main cause of this UTI in spinal cord injury population is considered to be indwelling catheter ${ }^{9}$. This is because indwelling catheter is used in over $77 \%$ cases of neurogenic bladder ${ }^{10}$.

Local study, was carried out seven years ago to find out frequency of UTI in patients of SCI with different voiding modes. However, we could not find any local study regarding the nosocomial urinary tract infection and the antibiotic susceptibility of such infections.

The rationale of this study was to determine the frequency of Nosocomial infection and its susceptibility to antimicrobial agents in order to manage these cases in better way using appropriate antibiotics.

\section{METHODOLOGY}

Using WHO calculator, confidence level $=95 \%$, Anticipated population proportion $=25 \% 10$, absolute precision $=8 \%$, sample size $=120$.

Non-probability, consecutive sampling technique was used in this study. The inclusion of this study was male and female patients of ages (18-70 years) with acute ( $>6$ months) or chronic ( $>6$ months) spinal cord injury admitted for rehabilitation and developing urinary tract infection 48 hours after admission. The exclusion of this study was Patients whose culture results have polymicrobicbacteriuria samples to rule out contamination. Patients having immune deficiency disorder. Patients getting any type of immunosup-pressive therapy.

Ethics committee approval was obtained from local hospital ethics committee. Inpatient record from admitted spinal cord injury patients having urinary tract infection during the hospital stay were included in the study over a period of one year. The data gathered from each patient included hospitalization date, development of UTI during hospital stay or not, the UTI was symptomatic or asymptomatic. Urine samples of all admitted patients suspected to have UTI were collected and send to Armed Forces Institute of Pathology for culture sensitivity test showing isolated causative microorganisms and their antibiotics susceptibility. Proforma attached as Annexure 'B'.

All the data collected was entered and analyzed in SPSS (version 20). Mean and standard deviation were calculated for quantitative variables like age and duration of hospital stay. Frequency and percentages were calculated for qualitative variables like gender, symptomatic \& asymptomatic UTI and antibiotic susceptibility.

Effect modifiers like age, gender, acute and chronic cases, symptomatic \& asymptomatic cases were controlled by stratification. Post stratification was done by applying chi-square test. A $p$-value of $<0.05$ was considered statistically significant.

\section{RESULTS}

About 18-70 years was the range of age for the study with mean age of $34.58 \pm 12.59$ years. Majority of the patients $96(80 \%)$ were between $41-40$ years of age.

Out of the 120 patients, $97(80.80 \%)$ were male and $23(19.20 \%)$ were females with male to female ratio of 4.2:1. Mean duration of hospital stay was $6.52 \pm 1.63$ days. Distribution of patients according to duration of injury and symptomatic \& asymptomatic UTI. Frequency of nosocomial urinary tract infections was found in $83(69.17 \%)$ and no nosocomial UTI in 37 (30.83\%) patients as shown in table-I.

Table-I: Distribution of patients according to nosocomial UTI $(n=120)$.

\begin{tabular}{l|c|c}
\hline Nosocomial UTI & No. of Patients & Percentage \\
\hline Yes & 83 & 69.17 \\
\hline No & 37 & 30.83 \\
\hline Total & 120 & 100.0 \\
\hline
\end{tabular}

Table-II: Antibiotic susceptibility in spinal cord injury patients.

\begin{tabular}{l|c|c}
\hline Antibiotic & Susceptible & Resistant \\
\hline Amikacin & $111(92.50 \%)$ & $09(7.50 \%)$ \\
\hline Gentam; icin & $108(90.0 \%)$ & $12(10.0 \%)$ \\
\hline Imipenem & $113(94.17 \%)$ & $07(5.83 \%)$ \\
\hline Tazocin & $115(95.83 \%)$ & $05(4.17 \%)$ \\
\hline Ceftriaxone & $105(87.50 \%)$ & $15(12.50 \%)$ \\
\hline Nitrofurantoin & $89(74.17 \%)$ & $31(125.83 \%)$ \\
\hline Ciprofloxacin & $96(80.0 \%)$ & $24(20.0 \%)$ \\
\hline
\end{tabular}

In this study, I have found thefrequency of antibiotic susceptibility in spinal cord injury patients as follows; Amikacin in 111 (92.50\%), Gentamicin in 108 (90.0\%), Imipenemin 113 (94.17\%), Tazocin in 115 $(95.83 \%)$, Ceftriaxone in 105 (87.50\%), Nitrofurantoin in $89(74.17 \%)$ and Ciprofloxacin in $96(80 \%)$ patients as shown in table-II.

Stratification of nosocomial urinary tract infections with respect to age, gender, duration of injury, and symptomatic \& asymptomatic UTI is shown in table-III. Table-IV has shown stratification of frequency 
of antibiotic susceptibility with respect to symptomatic

Table-III: Stratification of nosocomial urinary tract infection with respect to age, gender, duration of injury and symptoms.

\begin{tabular}{|c|c|c|c|c|}
\hline \multirow{2}{*}{\multicolumn{2}{|c|}{$\begin{array}{l}\text { Stratification With } \\
\text { Respect To }\end{array}$}} & \multicolumn{2}{|c|}{ Nosocomial UTI } & \multirow{2}{*}{$\begin{array}{c}p- \\
\text { value }\end{array}$} \\
\hline & & Yes & No & \\
\hline \multirow{2}{*}{ Age } & $\begin{array}{l}18-40 \text { years } \\
(n=55)\end{array}$ & $\begin{array}{c}47 \\
(85.45 \%)\end{array}$ & $\begin{array}{c}08 \\
(14.55 \%)\end{array}$ & \multirow{2}{*}{0.001} \\
\hline & $\begin{array}{l}41-65 \text { years } \\
(65)\end{array}$ & $\begin{array}{c}36 \\
(55.38 \%)\end{array}$ & $\begin{array}{c}29 \\
(44.62 \%)\end{array}$ & \\
\hline \multirow{2}{*}{ Gender } & Male & $\begin{array}{c}61 \\
(70.11 \%)\end{array}$ & $\begin{array}{c}26 \\
(22.89 \%)\end{array}$ & \multirow{2}{*}{0.715} \\
\hline & Female & $\begin{array}{c}22 \\
(66.67 \%)\end{array}$ & $\begin{array}{c}11 \\
(33.33 \%)\end{array}$ & \\
\hline \multirow{2}{*}{$\begin{array}{l}\text { Duration } \\
\text { of injury }\end{array}$} & $\begin{array}{l}\text { Acute } \\
(n=102)\end{array}$ & $\begin{array}{c}71 \\
(69.61 \%)\end{array}$ & $\begin{array}{c}31 \\
(30.39 \%)\end{array}$ & \multirow{2}{*}{0.803} \\
\hline & $\begin{array}{l}\text { Chronic } \\
(\mathrm{n}=18)\end{array}$ & $\begin{array}{c}12 \\
(66.67 \%) \\
\end{array}$ & $\begin{array}{c}06 \\
(33.33 \%) \\
\end{array}$ & \\
\hline \multirow{2}{*}{$\begin{array}{l}\text { Symp- } \\
\text { toms }\end{array}$} & $\begin{array}{l}\text { Symptomatic } \\
(\mathrm{n}=107)\end{array}$ & $\begin{array}{c}74 \\
(69.16 \%)\end{array}$ & $\begin{array}{c}33 \\
(30.84 \%)\end{array}$ & \multirow{2}{*}{0.996} \\
\hline & $\begin{array}{l}\text { Asymptomatic } \\
(\mathrm{n}=13)\end{array}$ & $\begin{array}{c}09 \\
(69.23 \%)\end{array}$ & $\begin{array}{c}04 \\
(30.77 \%)\end{array}$ & \\
\hline
\end{tabular}

Table-IV: Stratification of antibiotic susceptibility with respect to symptomatic \& asymptomatic UTI.

\begin{tabular}{|c|c|c|c|c|}
\hline & & $\begin{array}{c}\text { Symptomatic } \\
(\mathrm{n}=107)\end{array}$ & $\begin{array}{c}\text { Asymptomatic } \\
(n=13)\end{array}$ & $\begin{array}{c}p- \\
\text { value }\end{array}$ \\
\hline \multirow{2}{*}{ Amikacin } & $S$ & 99 (92.52\%) & $12(92.31 \%)$ & \multirow[t]{2}{*}{0.978} \\
\hline & $\mathrm{R}$ & $08(7.48 \%)$ & $01(7.69 \%)$ & \\
\hline \multirow{2}{*}{ Gentamicin } & $S$ & $95(88.79 \%)$ & $13(100 \%)$ & \multirow{2}{*}{0.203} \\
\hline & $\mathrm{R}$ & $12(11.21 \%)$ & - & \\
\hline \multirow{2}{*}{ Imipenem } & $S$ & $101(94.39 \%)$ & $12(92.31 \%)$ & \multirow{2}{*}{0.762} \\
\hline & $\mathrm{R}$ & $06(5.61 \%)$ & $01(7.69 \%)$ & \\
\hline \multirow{2}{*}{ Tazocin } & $S$ & $102(95.33 \%)$ & $13(100 \%)$ & \multirow{2}{*}{0.426} \\
\hline & $\mathrm{R}$ & $05(4.67 \%)$ & - & \\
\hline \multirow{2}{*}{ Ceftriaxone } & $S$ & $94(87.85 \%)$ & $11(84.62 \%)$ & \multirow{2}{*}{0.739} \\
\hline & $\mathrm{R}$ & $13(12.15 \%)$ & $02(15.38 \%)$ & \\
\hline \multirow{2}{*}{$\begin{array}{l}\text { Nitrofuran- } \\
\text { toin }\end{array}$} & $S$ & $81(75.70 \%)$ & 08 (61.54\%) & \multirow{2}{*}{0.271} \\
\hline & $\mathrm{R}$ & $26(24.30 \%)$ & $05(38.46 \%)$ & \\
\hline \multirow{2}{*}{$\begin{array}{l}\text { Ciproflo- } \\
\text { xacin }\end{array}$} & $S$ & $84(78.50 \%)$ & $12(92.31 \%)$ & \multirow{2}{*}{0.240} \\
\hline & $\mathrm{R}$ & $23(21.50 \%)$ & $01(7.69 \%)$ & \\
\hline
\end{tabular}

\& asymptomatic UTI.

\section{DISCUSSION}

People with spinal cord injuries have an increased risk of developing urinary tract infection (UTI). Presently, UTIs increase the morbitidy and mortality of patients having SCI. Improved management has decreased the mortality from urinary sepsis to $10-15 \%^{11-12}$. UTIs account for up to $40 \%$ of nosocomial infections, mainly due to catheterization. These result in bacteremia in $2-4 \%$ of patients, and increase the case fatality by three times when compared with non-bacteriuric patients 13,14. We have conducted this study to identify the freq- uency of nosocomial urinary tract infections and their antibiotic susceptibility in spinal cord injury patients.

Age range in this study was from 18-70 years with mean age of $34.58 \pm 12.59$ years. Majority of the patients $96(80 \%)$ were between $41-40$ years of age. Out of the 120 patients, $97(80.8 \%)$ were male and 23 $(19.2 \%)$ were females with male to female ratio of 4.2:1. Frequency of nosocomial urinary tract infections was found in $83(69.17 \%)$ and no nosocomial UTI in 37 $(30.83 \%)$ patients. In this study, I have found the frequency of antibiotic susceptibility in spinal cord injury patients as follows; Amikacin in 111 (92.50\%), Gentamicin in 108 (90.0\%), Imipenemin 113 (94.17\%), Tazocin in 115 (95.83\%), Ceftriaxone in $105(87.50 \%)$, Nitrofurantoin in $89(74.17 \%)$ and Ciprofloxacin in $96(80 \%)$ patients.In a study conducted by Amin and collegues it was seen that the most common isolates were E-coli and this bacterium was most sensitive to amikacin $(90.5 \%)$, ceftriaxone $(90.5 \%)$, gentamicin $(90.5 \%)$, ciprofloxacin $(85.3 \%)$ and nitrofurantoin $(71.2 \%)$. Amikacin and ciprofloxacin $(90.6 \%$ \& $85.9 \%$ respectively) were effective antibiotics against gram-positive $\operatorname{cocci}^{8}$. Main cause of this UTI in spinal cord injury population is considered to be indwelling catheter9 .

Patients with spinal cord injury (SCI) often have indwelling or intermittent urinary catheters and are prone to have asymptomatic bacteriuria and UTIs. As a result, they frequently receive antimicrobial therapy and have a higher prevalence of antibiotic resistant urinary tract isolates compared with patients without SCI ${ }^{13-15}$. Unfortunately, data are lacking to provide guidance for optimal treatment and duration for UTIs in patients with SCI. Many studies have evaluated patient propensity for development of antibiotic resistance in UTIs. Age $>65$ years, use of a urinary catheter, previous hospitalization, and prior antimicrobial use have been identified as common risk factors ${ }^{16,17}$. Waites and colleagues evaluated antimicrobial resistance of urinary tract organisms in outpatients with $\mathrm{SCI}$ and found that $33 \%$ of urinary cultures isolated multidrug-resistant microorganisms. The authors demonstrated a relationship between antimicrobial resistance and broad spectrum and prophylactic use of antibiotics ${ }^{18}$. In a study on spinal cord injury patients, Enterobacteriaceae were found in larger proportion in communitydwelling patients than in total urinary isolates from hospital-dwelling patients ( $85.5 \%$ vs $66 \%, p<0.001)$, however Pseudomonas, Acinetobacter and Enterococcus species were relatively less $(8.7 \%, 6 \%$ and $12 \%$ vs $2.8 \%, 0.7 \%$ and $2.8 \%$, respectively, $p<0.05)$. Susceptibi- 
lity of hospital-dwelling patients was less to ampicillin, amoxicillin-clavulanic acid, trimethoprim-sulfamethoxazole and all generations of cephalosporin $(p<0.05)$, and a higher prevalence of extended-spectrum betalactamase (ESBL)-producers (41.7 vs 5.4\%, $p<0.001$ ), than those from community-dwelling patients. Levofloxacin susceptibility was $<50 \%$ in both groups ${ }^{19}$.

Nicolle et $a l^{20}$, and Henderson et al21, reported that risk of nosocomial infection is more in SCI patients being treated in acute rehabilitation units in Canada. Infections of Urinary tract and skin/soft tissue were commonest $\mathrm{t}^{20,21}$. However, they did not mention specific data on organism responsible for nosocomial infectins, acute severity of illness at admission time and objective measures of functional status.

In another study, 276 patients were included, 159 had acute SCI and 117 had chronic SCS. 116 (61\%) had asymptomatic bacteriuria whereas 110 (39\%) had symptomatic urinary tract infection (SUTIs). E.coli and Pseudomonas were commonly isolated pathogens of SUTIs in patients of acute SCI; whereas E.coli was the commonest isolated pathogen in SUTIs and ASBs in patients of chornic SCI. The difference between acute and chronic SCI patients in rates of NAUTI (ASB and SUTI) in terms of bladder drainage method was statistically insignificant. Susceptibility ratio for E.coli in patients of acute and chronic SCI using Foley catheter was very low; however it was not that low in patients using clean intermittent catheterization ${ }^{22}$. Another study had 91 SCI patients with 53 males and 38 females having mean age of of $45.29 \pm 17.87$ years. Thirty eight SCI (41.7\%) patients developed 47 UTI episodes 9. patients had 2 episodes. Escherichia coli (57.4\%) was the commonest pathogen. Gentamicin (72.3\%), piperacillin /tazobactam (57.4\%), and meropenem (48.9\%) were most susceptible antibiotics ${ }^{23}$. Resistance to cotrimoxazole for E.coli has reached $50 \%$ and efficacy of empirical use of this antibiotic has reduced significantly. Resistance to ceftriaxone and ciprofloxacin in patients has also been recorded at approximately $28 \%$ and $48 \%$, respectively ${ }^{24}$.

\section{CONCLUSION}

The frequency of noso-comial UTI in SCI patients is quite high and tazocin and imipenem are the most sensitive antibiotics. So, we recommend that special care must be taken regarding appropriate antibiotics innosocomial UTI in SCI patients.

\section{CONFLICT OF INTEREST}

This study has no conflict of interest to be declared by any author.

\section{REFERENCES}

1. Compton S, Trease L, Cunningham C, Hughes D. Australian Institute of Sport and the Australian Paralympic Committee position statement: urinary tract infection in spinal cord injured athletes. Br J Sports Med 2015; 49(19): 1236-40.

2. Toga T, Azap O, Durukan E, Arslan H. The Prevalence, Etiologic Agents and Risk Factors for Urinary Tract Infection Among Spinal Cord Injury Patients. Jundishapur J Microbiol. 2014; 7(1): e8905-12.

3. Waites KB, Canupp KC, DeVivo MJ. Epidemiology and risk factors for urinary tract infection following spinal cord injury. Arch Phys Med Rehabil 1993; 74(7): 691-95.

4. Stamm WE. Catheter-associated urinary tract infections: epidemiology, pathogenesis, and prevention. Am J Med 1991; 91(3B): 65S-71S.

5. Mazaira J, Labanda F, Romero J. Epidemiología de la lesiónmedular y otrosaspectos. Rehabilitación (Madr) 1998; 32(1): 365-72.

6. Jahromi MS, Mure A, Gomez CS. UTIs in patients with neurogenic bladder. Curr Urol Rep 2014; 15(9): 433-35.

7. Yilmaz B, Yavuz F, Adiguzel E. Retrospective analysis of nosocomial urinary tract infections with spinal cord injury patients in a rehabilitation setting. Turk J Phys Med Rehab 2014; 60(1): 289-94.

8. Amin M, Mehdinejad M, Pourdangchi Z. Study of Bacteria isolated from Urinary Tract Infections and determination of their Susceptibility to Antibiotics. Jundishapur J Microbiol 2009; 2(1): 118-23.

9. Barbara W. Trautner. Management of catheter-associated urinary tract infection (CAUTI). Curr Opin Infect Dis 2010; 23(1): 76-82.

10. Yıldız N, Akkoç Y, Erhan B, Gündüz B, Yılmaz B, Alaca R, et al. Neurogenic bladder in patients with traumatic spinal cord injury: treatment and follow-up. Spinal Cord 2014; 52(1): 462-67.

11. Mahboob F, Ahmed N, Rathore F, Razzaq S. Frequency of Urinary Tract Infection (UTI) \& Commonest Causative Organisms in Spinal Cord Injury Patients With Various Voiding Modes. Pak Arm For Med J 2011; 61(3): 89-94.

12. Whiteneck GG, Charlifue SW, Frankel HL. Mortality, morbidity, and psychosocial outcomes of persons spinal cord injured more than 20 years ago Paraplejia, 1992; 30(1): 617-30.

13. Haley RW, Culver DH, White JW, Morgan WM, Emori TG. The nationwide nosocomial infection rate: a new need for vital statistics. Am J Epidemiol 1985; 121(2): 159-67.

14. Krieger JN, Kaiser DL, Wenzel RP. Urinary tract etiology of blood stream infections in hospitalized patients. J Infect Dis 1983; 148(1): 57-62.

15. Biering-Sorensen F, Bagi P, Hoiby N. Urinary tract infections in patients with spinal cord lesions: treatment and prevention. Drugs 2001; 61(1): 1275-87.

16. Mylotte JM, Graham R, Kahler L, Young L, Goodnough S. Epidemiology of nosocomial infection and resistant organisms in patients admitted for the first time to an acute rehabilitation unit. Clin Infect Dis 2000; 30(3): 425-32.

17. Waites KB, Chen Y, De Vivo MJ, Canupp KC, Moser SA. Antimicrobial resistance in gram-negative bacteria isolated from the urinary tract in community-residing persons with spinal cord injury. Arch Phys Med Rehabil 2000; 81(2): 764-69.

18. Hinkel A, Finke W, Botel U, Gatermann SG, Pannek J. Increasing resistance against antibiotics in bacteria isolated from the lower urinary tract of an outpatient population of spinal cord injury patients. UrolInt 2004; 73(2): 143-48.

19. Yoon SB, Lee BS, Lee KD, Hwang SI, Lee HJ, Han ZA. Comparison of bacterial strains and antibiotic susceptibilities in urinary 
isolates of spinal cord injury patients from the community and hospital. Spinal Cord 2014; 52(1): 298-01.

20. Nicolle LE, Buffet L, Alfien N, Tate R. Nosocomial infections on a rehabilitation unit in an acute care hospital. Infect Control Hosp Epidemiol 1988; 9(1): 553-58.

21. Henderson E, Ledgerwood D, Romance L. Nosocomial infections in short-term rehabilitation patients: a two centre study [abstract 52], Infect Control Hosp Epidemiol , 1996; 17(1): 24-28.

22. Yilmaz B, Yavuz F, Adigüzel E. Retrospective analysis of nosocomial urinary tract infections with spinal cord injury patients in a rehabilitation setting. Turk J Phys Med Rehab 2014; 60(2): 289-94.

23. Albayrak I, Çalışkan A, Levendoğlu F, Özerbil OM, Dağı HT. Characteristics of urinary tract infections in patients with spinalcord injuries hospitalized at a rehabilitation centre. Cyprus J Med Sci 2016; 1(1): 17-21.

24. Yürüyen C, Gürol Y, Kaleağasioğlu SF, Kaspar EC, Yilmaz G. Isolation rates and antibiotic susceptibilities of different Enterobacteriaceae species asurinary tract infection agents in Turkey: a systematic review. Turk J Med Sci 2017; 47(1): 979-86. 